\title{
EFFECT OF WATER CONTENT IN KNEADING METHOD OF SOLID DISPERSION TECHNIQUE FOR SOLUBILITY ENHANCEMENT
}

\author{
SHANKARGURU P., RAMYA DEVI D, VEDHA HARI B. N.*
}

Department of Pharmaceutical Technology, School of Chemical and Biotechnology, SASTRA University, Thanjavur 613401, Tamil Nadu, India Email: vedhahari@scbt.sastra.edu

Received: 15 Feb 2017, Revised and Accepted: 22 Aug 2017

\section{ABSTRACT}

Objective: The main objective of the research work was to optimize the water requirement/content used in kneading method for solid dispersion/inclusion complex formation between water insoluble drug and polymer.

Methods: Nimesulide (model drug) and $\beta$-cyclodextrin were taken in a different ratio such as 1:1, 1:3 and 1:5 and, the mixture was triturated well for half hour. Water was incorporated to the mixture in different levels like $75 \%, 50 \%, 25 \% \mathrm{w} / \mathrm{v}$ in divided proportions and $0 \%$ (no water addition, but the mixture was triturated continuously). After each part of water addition, the mixture was triturated well for 10 min and dried using hot air over for $30 \mathrm{~min}$ at $50{ }^{\circ} \mathrm{C}$ and sieved using sieve no: 44. The complexes formed were subjected for various analytical characterization studies including solubility, particle size, the angle of repose, tapped density, Carr's index, fourier transform infrared spectrometry (FTIR), thermo gravimetric-differential thermal analysis (TG-TDA), $\mathrm{x}$-ray diffraction (XRD) studies and in vitro dissolution studies.

Results: The dissolution studies showed improvement in the release of nimesulide, which depended on the percentage level of water. The solubility of the sample was increased with increasing the concentration of the inclusion complex formed. Kneading method was proved to be a successful technique for formation of stable inclusion complex of nimesulide with $\beta$-cyclodextrin. All the formulations exhibited acceptable particle size and solubility in the range of $22.6 \pm 2$ to $29 \pm 5$ and $45 \pm 5$ to $133 \pm 3.5$ respectively.

Conclusion: Nimesulide and $\beta$-cyclodextrin complex was successfully prepared and characterized for the drug-polymer stability and interactions. The result confirmed that the liquid content in the solid dispersion prepared by the kneading method played an important role in the dissolution of the poorly soluble drug.

Keywords: Nimesulide, $\beta$-cyclodextrin, Solid dispersion, Kneading method

(C) 2017 The Authors. Published by Innovare Academic Sciences Pvt Ltd. This is an open access article under the CC BY license (http://creativecommons.org/licenses/by/4.0/) DOI: http://dx.doi.org/10.22159/ijap.2017v9i5.17765

\section{INTRODUCTION}

Nimesulide $(\mathrm{NM})$ is one of the potent non-steroidal antiinflammatory drugs (NSAIDs), widely prescribed for various antiinflammatory conditions. NM has categorized under class II drugs of the biopharmaceutical classification system (BCS) that illustrate poor aqueous solubility, which is the main reason for its low and variable oral bio availability [1-3]. NM is an acidic drug that differs from many similar compounds, by virtue of the presence of sulfoanilide group rather than a carboxyl group. Chemically it is named as [4-nitro-2-(phenoxy) methane sulphoanilide] (fig. 1).

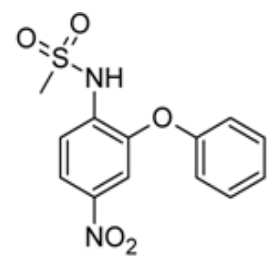

Fig. 1: Structure of nimesulide [2]

Pharmacologically NM is an inhibitor of cyclo-oxygenase-2 (COX-2) enzyme, and hence inhibits the synthesis of critical prostaglandins and spares cytoprotective prostaglandins. It can also inhibit the process involved in platelets aggregation [4-6].

The oral absorption of NM is dissolution rate limited, and hence enhancement in solubility and dissolution rate is required for increasing its oral bioavailability [7]. Among different methods reported for improving the solubilization of NM, the formation of an inclusion complex with cyclodextrins (CDs) (fig. 2) has been identified as the most common and successful approach. CDs exhibit a hydrophilic outer surface and lipophilic inner cavity with a cyclic torus shape, which is capable of interacting with a large variety of guest molecules to form an inclusion complex. CDs are commonly used in drug formulations as solubility enhancers because of their ability to form water soluble complexes with poorly water soluble drugs. They also have huge potential as carrier molecules in the formulation of novel drug delivery systems. The inclusion complexes can modify pharmacokinetic properties of guest molecules by fitting within the hydrophobic cavity of CDs $[8,9]$. Several NSAIDs have been complexed with CDs, which resulted in high solubility and dissolution rate, decreased side effects, reduced dose, improved bioavailability and stability, lesser gastric irritation and also enhanced the palatability of the active molecules [10-13].

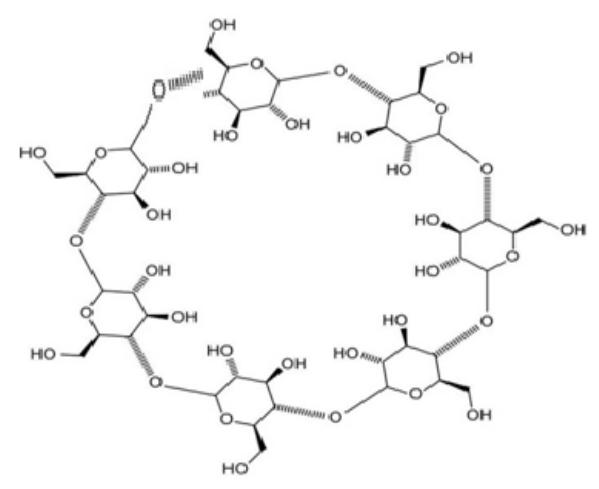

Fig. 2: Structure of $\beta$-cyclodextrin [12]

Kneading is one of the common methods used in solid dispersion technique for the enhancement of solubility and dissolution rate of 
poorly soluble drugs. The process involves reduction of particle size at the molecular level through complexation of the freely water soluble chemically inert carriers with the guest molecule (drug). The formed product could result in better therapeutic effect due to improved solubility and increased bioavailability. During the kneading process, the addition of few drops of water to the triturated drug and inert polymer mixture helps in complete complexation between drug and polymer. The addition of water aids in dissolving the freely water soluble carrier which allows the drug to enter into the molecular domain, followed by trituration helps in reducing particle size up to sub-micron level. Thus, the combination of complexation and size reduction may double the effect for the enhancement of solubility $[14,15]$. The aim of the present study was to prepare NM complexes with CDs by kneading method and study the effect of water level added in the solid dispersion process for the enhancement of solubility of the drug.

\section{MATERIALS AND METHODS}

\section{Materials}

Nimesulide was purchased from Chatan and Chatan Ltd., Chennai, India. $\beta$-cyclodextrin was procured from SD Fine Chem Ltd., Mumbai, India. All other chemicals and reagents used were of analytical grade.

\section{Methods}

Nimesulide and $\beta$-cyclodextrin were taken in different ratios such as $1: 1,1: 3,1: 5$ (table 1) and triturated well for uniform mixing of the powders. Water was added in different concentration as $25 \%, 50 \%$, and $75 \% \mathrm{w} / \mathrm{v}$ to study the optimized level of water content required in the kneading process. In each ratio of the mixture, one batch was needed without the addition of water. The required amount of total water was divided into proportionate parts and added to the powder mixture at periodic intervals of $10 \mathrm{~min}$. After each addition of water, the mixture was triturated uniformly for $30 \mathrm{~min}$ and dried [16]. At the end of the final addition of water, the mixture was further dried and then sieved using sieve no: 44 . The prepared complex samples were stored at ambient conditions for further studies.

\section{Particle size analysis of the kneaded mixture}

The particles size and distribution of all the formulations were analysed by optical microscope method. The formulated kneaded dry powder sample was placed over a clean glass slide and focused at $10 \mathrm{X}$ and $40 \mathrm{X}$ magnifications to view the particles. The size of the particles was measured with an eye piece micrometer previously calibrated using the stage micrometer [17].

Table 1: Optimization of water in kneading method for nimesulide and $\beta$-cyclodextrin complexation

\begin{tabular}{|c|c|c|c|c|}
\hline S. No. & Formulation code & Drug (g) & Carrier (g) & Water $(\% \mathrm{w} / \mathrm{v})$ \\
\hline 1 & KN1 & 1 & 1 & 25 \\
\hline 2 & KN2 & 1 & 1 & 50 \\
\hline 3 & KN3 & 1 & 1 & 75 \\
\hline 4 & KN4 & 1 & 1 & NW \\
\hline 5 & KN5 & 1 & 3 & 25 \\
\hline 6 & KN6 & 1 & 3 & 50 \\
\hline 7 & KN7 & 1 & 3 & 75 \\
\hline 8 & KN8 & 1 & 3 & NW \\
\hline 9 & KN9 & 1 & 5 & 25 \\
\hline 10 & KN10 & 1 & 5 & 50 \\
\hline 11 & KN11 & 1 & 5 & 75 \\
\hline 12 & KN12 & 1 & 5 & NW \\
\hline 13 & PT13 & 1 & - & - \\
\hline 14 & NP14 & 1 & - & - \\
\hline
\end{tabular}

KN 1-12-Kneaded complex of nimesulide and cyclodextrin, NW-No Water added, NP-Nimesulide pure drug (unprocessed) and PT-Nimesulide pure drug in triturated form

\section{Physical and derived properties of kneaded mixture}

\section{Angle of repose}

In order to evaluate the flow properties of the formulations prepared by the kneading method, angle of repose, bulk density, tap density and Carr's index were calculated.

Angle of repose $(\theta)$ was determined using funnel method to assess the flow behaviour of the sample. The powder sample was poured through a funnel placed at the height of about $3 \mathrm{~cm}$ from the base plane and allowed to form a heap. The height and diameter of the formed heap were noted and angle of repose was calculated using the formula [18].

$$
\theta=\tan ^{-1}\left(\frac{h}{n}\right)
$$

Where, $\mathrm{h}=$ height: $\mathrm{r}=$ radius of the heap. The experiment was conducted in triplicate and the mean \pm standard deviation was estimated.

\section{Bulk density}

The triturated final sample was accurately weighed and poured into a clean, dry measuring cylinder and the bulk volume was noted. The cylinder was then tapped 300 times from a constant height and the tapped volume was recorded. The bulk density and tapped density were calculated with respect to the known weight of the sample taken for the analysis, using the formula $[18,19]$.

$$
\text { Bulk density }=\frac{\text { Weight of substance }}{\text { Bulk volume }}
$$

$$
\text { Tap dens:ty }=\frac{\text { Woight of the substance }}{\text { Tapped wlume }}
$$

\section{Carr's index}

Carr's index is a measure to indicate the nature of the sample and its suitability to convert as tablets by tablet compression process. The stability and dose specificity of the kneading mixture could be improved by formulating as tablets. Carr's index was calculated from the values of bulk density and tapped density of the formulation using the formula [19].

$$
\text { Carrs index }=\frac{\text { Tap density }- \text { Bulk density }}{\text { Tah density }} \times 100
$$

\section{Solubility test}

The solubility of the kneaded samples was analysed and compared to the pure drug, by shake flask method using the thermostatic shaker. About $1 \mathrm{mg}$ of NM and the kneaded mixture was placed in 5 $\mathrm{ml}$ sample tube and $2 \mathrm{ml}$ of distilled water was added to each separately. The tubes were placed on the shaker and continued shaking (Incubator shaker Edison, NJ, USA) for $24 \mathrm{~h}$ at $150 \mathrm{rpm}$ at room temperature. The samples were taken out and then centrifuged at $4500 \mathrm{rpm}$ at $4{ }^{\circ} \mathrm{C}$ for $10 \mathrm{~min}$. The supernatant of each sample was collected separately, suitably diluted and the concentration of drug was measured using UV spectrophotometer (Evolution 201, Thermo Scientific, USA) at $397 \mathrm{~nm}$ [20]. 


\section{In vitro dissolution studies}

The rate of drug dissolution from the formulated solid dispersion was studied by USP dissolution method. The powder samples were dried and sieved and then filled in hard gelatin capsule shells (size no. 1). The capsules were placed in the basket of USP type-I dissolution apparatus (Lab India, Mumbai) containing $900 \mathrm{ml}$ of distilled water as the media. The dissolution set up was maintained at $50 \mathrm{rpm}$ speed and $37{ }^{\circ} \mathrm{C} \pm 2{ }^{\circ} \mathrm{C}$ for $60 \mathrm{~min}$. At predetermined time intervals such as 10,20,30,40,50 and $60 \mathrm{~min}$, the samples were withdrawn and the media was replaced with warm fresh distilled water after each withdrawal, to maintain the sink conditions. The collected samples were suitably diluted and the concentration of drug was measured using UV-visible spectrophotometer at $397 \mathrm{~nm}$ [20] using distilled water as the blank. The cumulative amount of drug released at each time point was calculated using the linear standard calibration curve method. The experiment was conducted in triplicate and the mean \pm standard deviation was recorded.

\section{Powder X-ray diffraction}

Samples of NM-CD complex prepared by kneading method with different levels of water were evaluated by X-ray powder diffraction analysis. The pure NM and kneaded samples were individually loaded in the sample cavity of the X-ray diffractometer (Ultima-3, Rigaku) and the diffraction patterns were obtained using with $\mathrm{Cu}$ radiation. The system was used with diverging and receiving slits of 1 and $0.1 \mathrm{~mm}$, respectively. The pattern was observed with $40 \mathrm{kV}$ of tube voltage and $30 \mathrm{~mA}$ of tube current and scanned over the $2 \theta$ range of $10^{\circ}-80^{\circ}[21]$.

\section{Drug content}

The accurately weight quantity of kneaded powder sample was taken equivalent to the drug dose filled in a capsule and dissolved in $50 \mathrm{ml}$ of methanol. The sample was diluted suitably and the absorbance was measured using UV-visible spectrophotometer at $397 \mathrm{~nm}$. The percentage of drug content was calculated by using the standard calibration method [21].

$$
\% \text { Drug Content }=\frac{\text { Sample Absorbance }}{\text { Standard Absorbance }} \times 100
$$

\section{Fourier transforms infrared spectroscopy (FTIR)}

FTIR (Perkin-Elmer system 200 FT-IR spectrophotometer) analysis was performed in order to find out the interaction between the drug and the polymers and thus the stability of drug could be confirmed. IR analysis of the sample reveals the presence of the characteristic functional group in the pure samples and the possible interaction in the mixture samples that could be compared to the original spectrum. It was performed by $\mathrm{KBr}$ pellet technique in which the samples were mixed with previously dried, saturated potassium bromide, and then pressed under a hydraulic pressure of 150 $\mathrm{kg} / \mathrm{cm}^{2}$ to form thin transparent disc pellet. The disc was placed in the IR sample holder and scanned over a range of 3600 to $400 \mathrm{~cm}^{-1}$ at ambient temperature $[22,23]$.

\section{Thermal analysis}

The thermal characteristics of the samples were analysed using thermo gravimetric and differential thermal analysis (TG-DTA) (SDT Q600 V20.9 Build 20). About $10 \mathrm{mg}$ of the sample was placed in aluminium pan and then heated under nitrogen flow $(20 \mathrm{ml} / \mathrm{min})$ [24], at the rate of $10^{\circ} \mathrm{C} / \mathrm{min}$ within a range of $0{ }^{\circ} \mathrm{C}$ to $500{ }^{\circ} \mathrm{C}$. TGA is one of the thermal analysis techniques used to characterise a wide variety of materials, which provides complimentary and supplementary information like differential scanning calorimetry (DSC) [25]. The technique can analyze materials that exhibit either mass loss or gain due to decomposition, oxidation or loss of volatiles [26, 27].

\section{RESULTS AND DISCUSSION}

\section{Particle size analysis}

The particle size of the formulations prepared by kneading method was analysed using an optical microscope and reported in table 2 . The maximum number of particles in the kneaded complex was observed to be in the narrow size range of 22 to $29 \mu \mathrm{m}$. There was no significant difference in the particle size of the pure drug with respect to the unprocessed sample (NP14-23.4 $\mu \mathrm{m}$ ) and the kneaded sample (PT13-22.6 $\mu \mathrm{m})$. In case of the NM-CD complex mixture, the addition of water had played a notable role in size reduction of the samples. The sample prepared with 1:1,1:3 and 1:5 ratio without the addition of water (NW) have shown slightly larger sized particles in the range of $26-29 \mu \mathrm{m}$, whereas the water kneaded complex showed comparatively lesser size in each set of batches. This could be due to the easier solubilization of the carrier to the molecular level by the addition of water and kneading, which reduced the size and increased the effective surface area followed by the incorporation of the insoluble drug to form the inclusion complex.

\section{Solubility test}

Solubility test results are shown in table 2 . The solubility of the unprocessed pure drug was $45.34 \mathrm{mg} / \mathrm{ml}$, whereas the triturated drug showed slightly higher solubility as $52.5 \mathrm{mg} / \mathrm{ml}$. In case of the NM-CD complex, there was a significant increase in the solubility of the drug compared to the pure drug, with minimum solubility range as $72.5 \mathrm{mg} / \mathrm{ml}$ and maximum up to $153.75 \mathrm{mg} / \mathrm{ml}$. Although there was a notable increase in the solubility of a kneaded complex of NMCD (KN4, KN8 and KN12) without the addition of water (NW) compared to the pure drug, the solubility was still lesser than the kneading complex samples containing water. When the kneaded complex prepared with the addition of different levels of water $(25 \%$, $50 \%, 75 \% \mathrm{w} / \mathrm{v}$ ) were compared within each respective batches, the samples containing $50 \% \mathrm{w} / \mathrm{v}$ water was found to have optimum higher solubility. The increase in water addition to next level of $75 \% \mathrm{w} / \mathrm{v}$ could not increase the solubility of drug further, which may be due to the saturation solubility level of the formed complex of NM with CD.

\section{Drug content}

The drug content assay for all the solid dispersion was within the pharmacopeia limits of around $95-110 \%$, as shown in table 2 .

Table 2: Solubility, particle size and drug content of the formulations

\begin{tabular}{lllll}
\hline S. No. & Formulation code & Solubility $(\mathbf{m g} / \mathbf{m l})$ & Particle size $(\boldsymbol{\mu m})$ & Assay (\%) \\
\hline 1 & KN1 & $72.5 \pm 5$ & $23.8 \pm 1.5$ & $105.9 \pm 1$ \\
2 & KN2 & $91.5 \pm 3$ & $24.2 \pm 2$ & $102.7 \pm 3$ \\
3 & KN3 & $79.25 \pm 5.5$ & $24.6 \pm 4$ & $95.9 \pm 4$ \\
4 & KN4 & $68 \pm 2.5$ & $26.2 \pm 3$ & $95.4 \pm 5$ \\
5 & KN5 & $95.25 \pm 5$ & $26.6 \pm 8$ & $96.1 \pm 2$ \\
6 & KN6 & $130.75 \pm 9$ & $24.2 \pm 6$ & $106 \pm 4$ \\
7 & KN7 & $107.25 \pm 4$ & $26.4 \pm 2$ & $109.4 \pm 1$ \\
8 & KN8 & $86 \pm 5.6$ & $29.8 \pm 5$ & $96.9 \pm 5$ \\
9 & KN9 & $118.25 \pm 5$ & $24.6 \pm 4$ & $95.5 \pm 4$ \\
10 & KN10 & $133.75 \pm 3.5$ & $25.8 \pm 3$ & $97.7 \pm 2.5$ \\
11 & KN11 & $124.25 \pm 10$ & $23.8 \pm 2$ & $95.6 \pm 53$ \\
12 & KN12 & $103.75 \pm 3.8$ & $29 \pm 5$ & $110 \pm 1$ \\
13 & PT13 & $52.5 \pm 4$ & $22.6 \pm 2$ & $97.6 \pm 4$ \\
14 & NP14 & $45.34 \pm 5$ & $23.4 \pm 3$ & $96.8 \pm 3$ \\
\hline
\end{tabular}

KN 1-12-Kneaded complex of nimesulide and cyclodextrin, NP-Nimesulide pure drug (unprocessed) and PT-Nimesulide pure drug in triturated form. The data is given as mean $\pm \operatorname{SD}(n=3)$ 


\section{Physical properties}

The flow properties of the kneaded formulations were calculated by using the angle of repose, bulk density, tap density and Carr's index (table no. 3) and compared with the pure drug. Bulk property of the powders depends on inter particulate interaction, which interferes with the powder flow behaviour [28]. The unprocessed pure drug exhibits poor flow behaviour because of excessive cohesive forces and non-uniform particle size. However, the triturated pure drug has shown better flow property. Similarly, in case of the kneaded mixture without the addition of water, the angle of repose value was $>30$, which indicated poor flow due to the improper complex formation and non-uniform distribution of the drug in the carrier. In case of the kneaded complex with the addition of water, the angle of repose $<30$ indicated good flow property, wherein water played an important role for the formation of uniform inclusion complex [29, 30]. Accordingly, the tapped density, bulk density and Carr's index were observed to be suitable for processing the complex mixture into a single unit solid dosage form like tablets by compression process or filling as a compact powder in capsules.

Table 3: Physical properties of NM-CD kneaded samples compared to pure drug

\begin{tabular}{lllll}
\hline S. No. & Formulation code & Angle of repose $(\boldsymbol{\theta})$ & Tapped density $(\mathbf{g m} / \mathbf{m l})$ & Bulk density $(\mathrm{gm} / \mathbf{m l})$ \\
\hline 1 & KN1 & $15 \pm 0.331$ & $0.617 \pm 0.046$ & $0.273 \pm 0.005$ \\
2 & KN2 & $16 \pm 0.816$ & $0.695 \pm 0.057$ & $0.277 \pm 0.023$ \\
3 & KN3 & $16 \pm 0.209$ & $0.565 \pm 0.021$ & $0.328 \pm 0.027$ \\
4 & KN4 & $31 \pm 0.500$ & $0.62 \pm 0.023$ & $0.314 \pm 0.012$ \\
5 & KN5 & $30 \pm 0.318$ & $0.601 \pm 0.026$ & $0.338 \pm 0.008$ \\
6 & KN6 & $30 \pm 0.723$ & $0.563 \pm 0.046$ & $0.359 \pm 0.019$ \\
7 & KN7 & $30 \pm 0.828$ & $0.66 \pm 0.066$ & $0.357 \pm 0.036$ \\
8 & KN8 & $38 \pm 0.789$ & $0.592 \pm 0.026$ & $0.305 \pm 0.013$ \\
9 & KN9 & $28 \pm 0.546$ & $0.659 \pm 0.021$ & $0.417 \pm 0.016$ \\
10 & KN10 & $27 \pm 0.424$ & $0.065 \pm 0.021$ & $0.506 \pm 0.126$ \\
11 & KN11 & $25 \pm 0.942$ & $0.702 \pm 0.024$ & $0.466 \pm 0.013$ \\
12 & KN12 & $46 \pm 0.834$ & $0.658 \pm 0.021$ & $43.50 \pm 3.53$ \\
13 & PT13 & $13 \pm 0.236$ & $0.633 \pm 0.047$ & $45.33 \pm 3.99$ \\
14 & NP14 & $42 \pm 1.220$ & $0.429 \pm 0.017$ & $36.70 \pm 0.56$ \\
\hline
\end{tabular}

KN 1-12-Kneaded complex of nimesulide and cyclodextrin, NP-Nimesulide pure drug (unprocessed) and PT-Nimesulide pure drug in triturated form. The data is given as mean $\pm \mathrm{SD}(\mathrm{n}=3)$

\section{In vitro dissolution studies}

The in vitro dissolution study results of the various ratio of kneading method complex (NM-CD) are shown in fig. 3, 4 and 5. The unprocessed pure drug sample showed the very slow dissolution of less than $20 \%$ at the end of $60 \mathrm{~min}$. In case of the pure drug in triturated (PT) form and also the kneaded mixture of drug: a carrier with no water (NW) content, the dissolution of the drug was poor. The data showed a significant increase in the percentage drug release with an increase in the water level of the formulation from 25 to $50 \% \mathrm{w} / \mathrm{v}$ in all the three ratios of drug: carrier mixture $(1: 1$, $1: 3$ and $1: 5)$. However, at $75 \% \mathrm{w} / \mathrm{v}$ water addition in the mixture, the dissolution of the drug was not varied notably which was due to the saturation solubility level of the drug: carrier mixture, as reported in the solubility study results. The results proved that the percentage of water added in the kneading mixture played a crucial role in the in vitro release of the drug from the mixture. Water helps to form a strong inclusion complex of drug with CDs at the optimum solvent concentration. Based on the results obtained, the formulation prepared with $50 \% \mathrm{w} / \mathrm{v}$ water level were considered as the optimum formulation and selected for further characterization studies.

\section{Fourier transforms infrared spectroscopy}

Infra red spectra of the pure drug and inclusion complexes of NM with $\beta$-CDs $(1: 1,1: 3$ and $1: 5)$ prepared by kneading method are given in fig. 6, 7, 8 and 9, respectively. The pure drug exhibited the characteristic peaks as the identity of the specific functional groups present in it. The sharp peaks observed at $3283 \mathrm{~cm}^{-1}, 1589 \mathrm{~cm}^{-1}$, $1153 \mathrm{~cm}^{-1}$ and $1273 \mathrm{~cm}^{-1}$ indicated the $\mathrm{N}-\mathrm{H}$ stretching of amide, aromatic $\mathrm{NO}_{2}$ stretching, $\mathrm{S}=\mathrm{O}$ stretching of sulphoxide and $\mathrm{C}-\mathrm{O}-\mathrm{C}$ stretching between the aromatic rings, respectively. Also, the presence of- $\mathrm{CH}_{3}$ and aromatic rings were confirmed by the corresponding stretching and bending vibrations. In case of all the kneaded inclusion complex samples (1:1, 1:3 and 1:5), the guest drug molecules present within the CDs cavity showed less intense peaks compared to the pure drug alone. The characteristic peaks of the drug were observed for the presence of $\mathrm{N}-\mathrm{H}, \mathrm{NO}_{2}, \mathrm{~S}=\mathrm{O}$ and $\mathrm{C}-\mathrm{O}-\mathrm{C}$ groups in the inclusion complex. The broad peak between the range of $3300 \mathrm{~cm}^{-1}$ and $3500 \mathrm{~cm}^{-1}$ showed the formation of intermolecular and intra molecular hydrogen bonding between the drug and $\beta$-CD $[30-32]$. These bonds were responsible for the mild interactions and formation of a stable complex of drug and carrier, without significant chemical reactions.

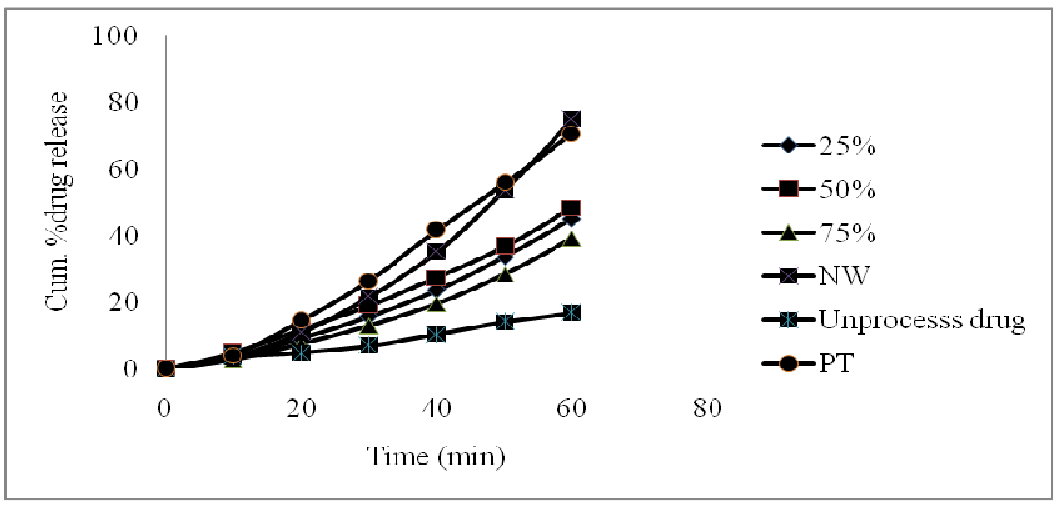

Fig. 3: In vitro drug release profile of kneading complex of NM with CD at 1:1 ratio (n=3) 


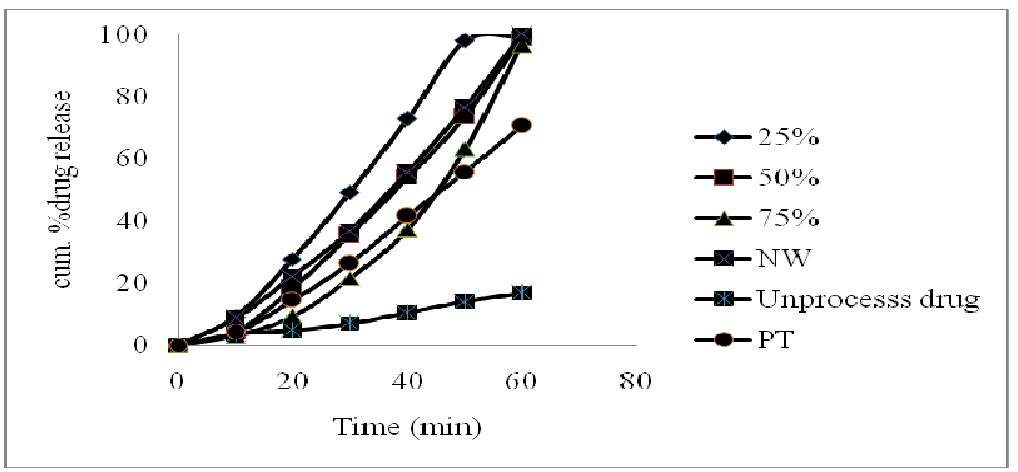

Fig. 4: In vitro drug release profile of kneading complex of NM with CD at 1:3 ratio $(n=3)$

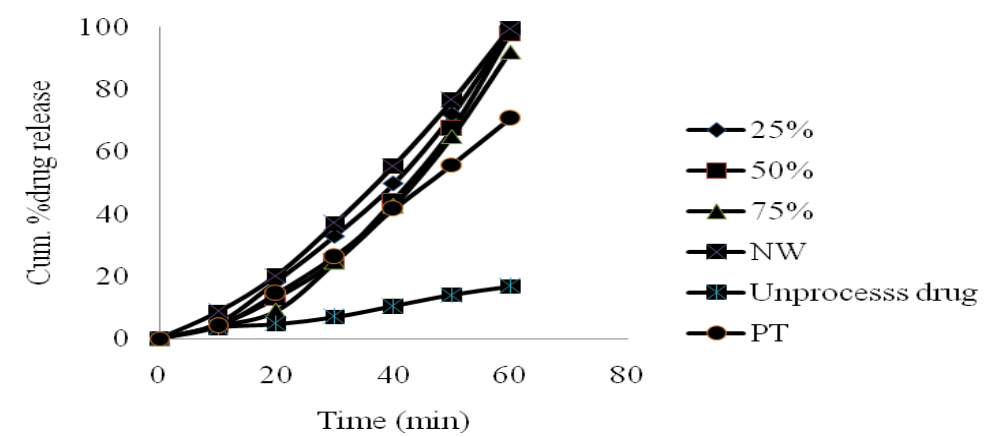

Fig. 5: In vitro drug release profile of kneading complex of NM with CD at 1:5 ratio (n=3)

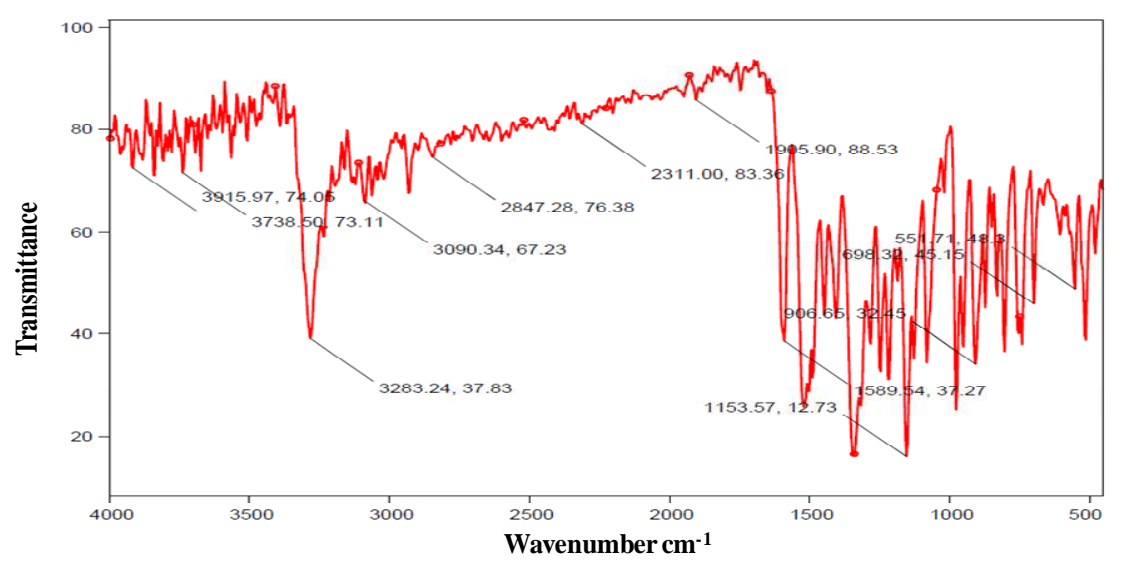

Fig. 6: FTIR spectrum of pure drug

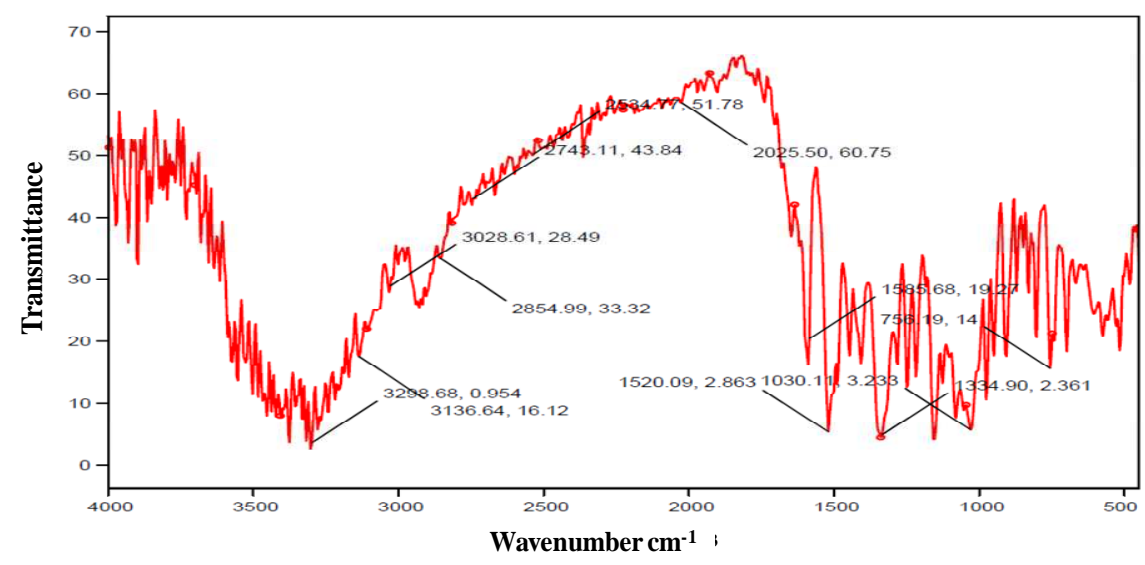

Fig. 7: FTIR spectrum of kneaded complex of NM with CD at 1:1 ratio 


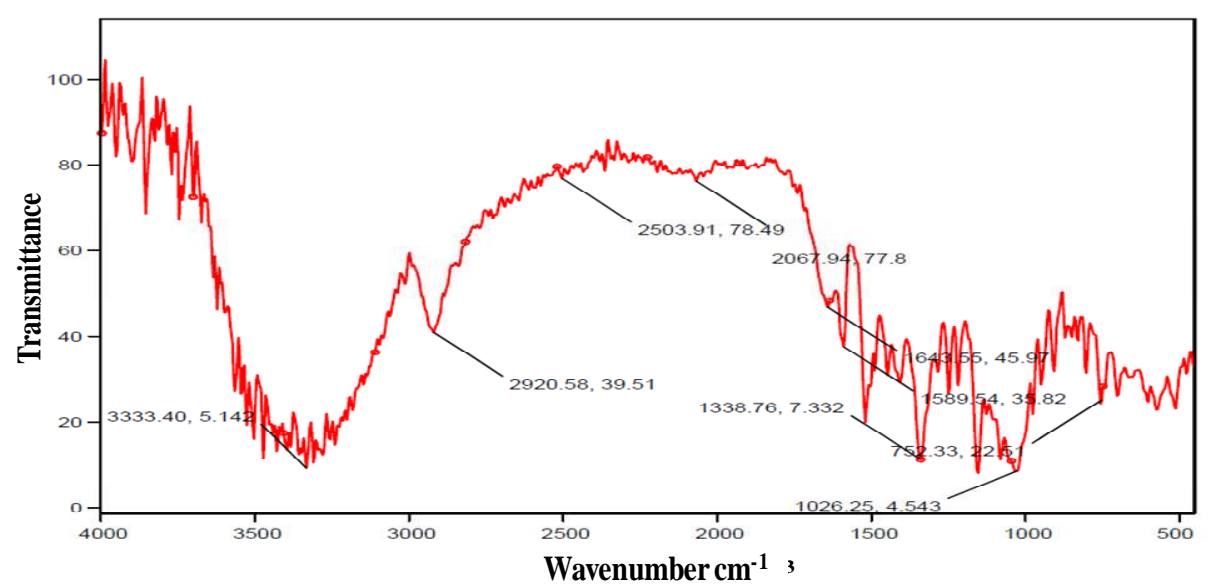

Fig. 8: FTIR spectrum of kneaded complex of NM with CD at 1:3 ratio

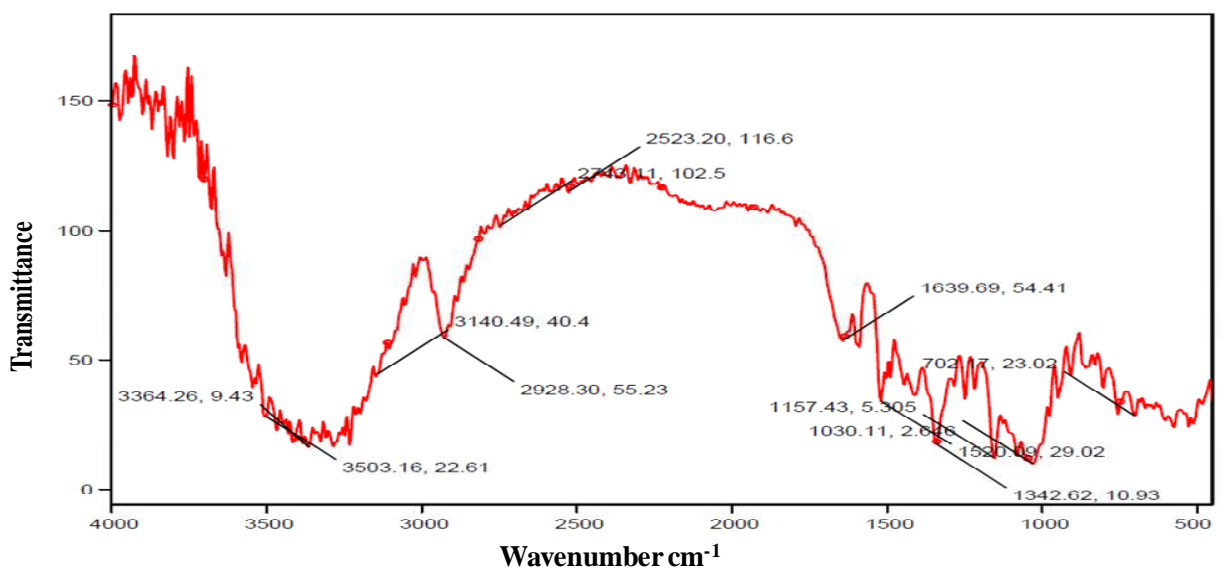

Fig. 9: FTIR spectrum of kneaded complex of NM with CD at 1:5 ratio

\section{Thermal analysis}

NM and $\beta$-CDs complex prepared by the kneading method was subjected to TG-DTA analysis and the results are given in fig. 10 and 11. Pure powder drug showed a sharp endothermic peak at
$150.10{ }^{\circ} \mathrm{C}$, the characteristic melting point of the drug. Further increase in the temperature resulted in the exothermic peak at around $335{ }^{\circ} \mathrm{C}$ and a corresponding sudden weight loss in the TG curve at the same temperature, which indicated the decomposition temperature of the drug.

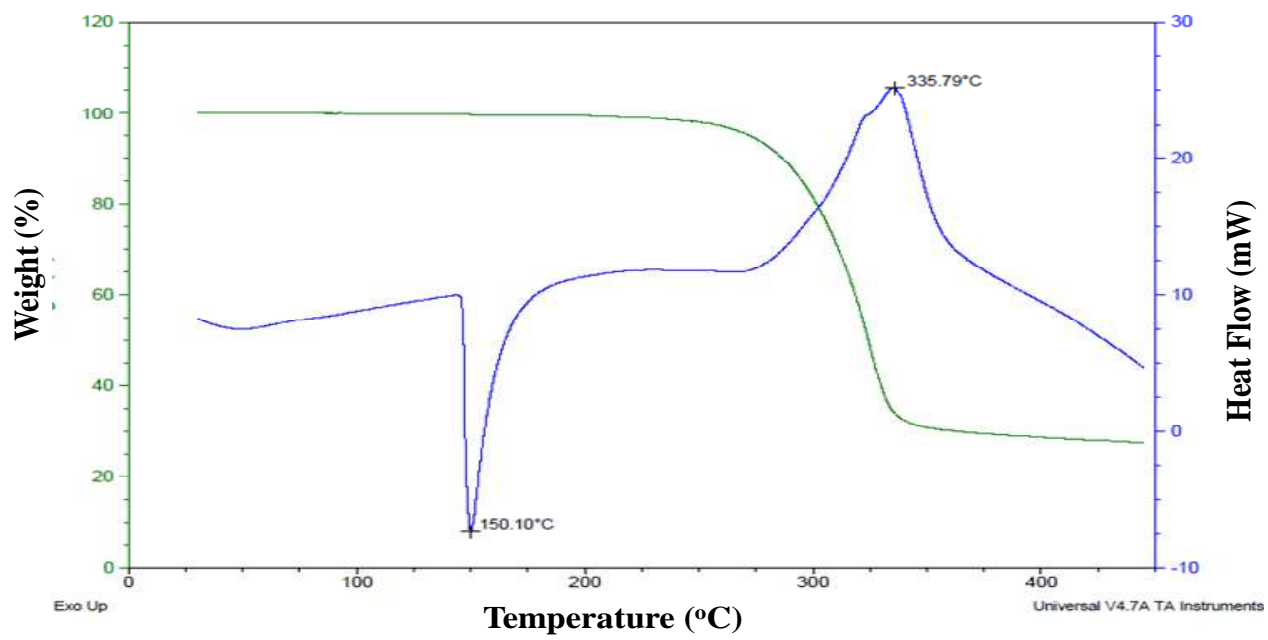

Fig. 10: Thermo gravimetric-differential thermal analysis of pure drug 


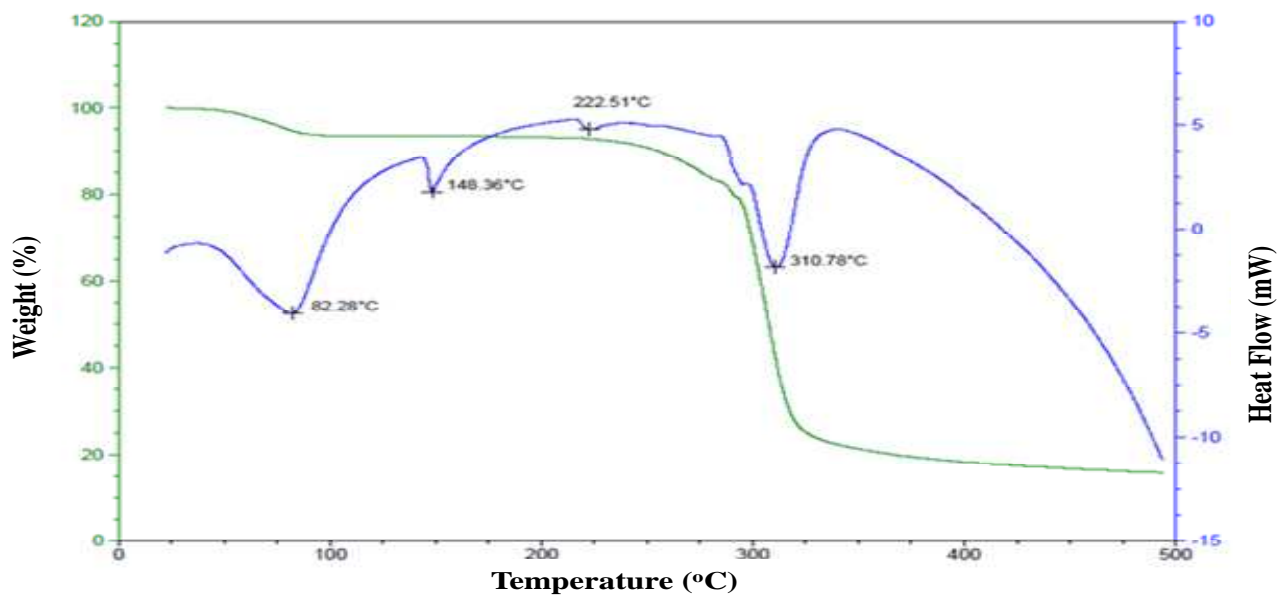

Fig. 11: Thermo gravimetric-differential thermal analysis of NM-CD kneaded complex

In case of the kneaded complex of drug: carrier, the endothermic peak of the drug was slightly shifted and hence the melting point was observed at $148.36^{\circ} \mathrm{C}$. The slight shift was probably due to a weak interaction between the host and guest molecules [31]. Additionally, the thermal properties of cyclodextrin were recorded, wherein the endothermic peat at around $82{ }^{\circ} \mathrm{C}$ represented the melting point of the polymer. Finally, the sample showed the decomposition temperature at $310{ }^{\circ} \mathrm{C}$ with corresponding sudden weight loss in the TG curve.

\section{Powder X-ray diffraction studies}

The XRD study results are displayed in fig. 12 and 13 for the pure drug and the kneaded complex formulation, respectively. The pure drug exhibited sharp peaks at $21.800,22.740$ and 23.260 with high intensity, which reflected the crystalline character of pure nimesulide. In case of the kneaded complex, the characteristics of both the drug and polymer were observed. Since the drug was encapsulated as inclusion complex in the carrier, the crystallinity of the drug was slightly altered. However, the sharp peaks in the formulated complex indicated the purity and crystal character of drug and the carrier [33, 34].

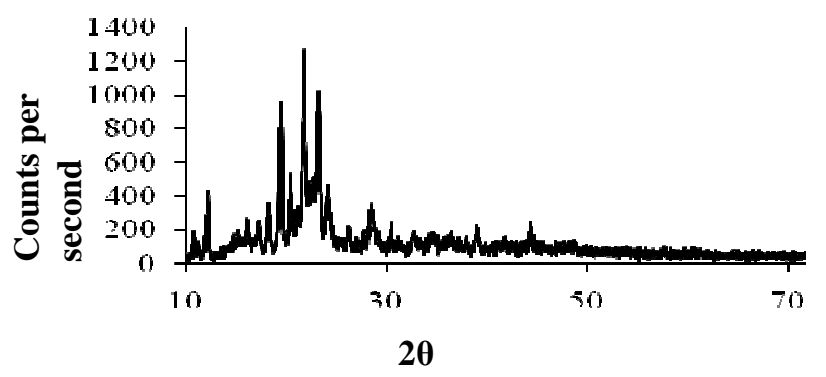

Fig. 12: XRD pattern for pure drug

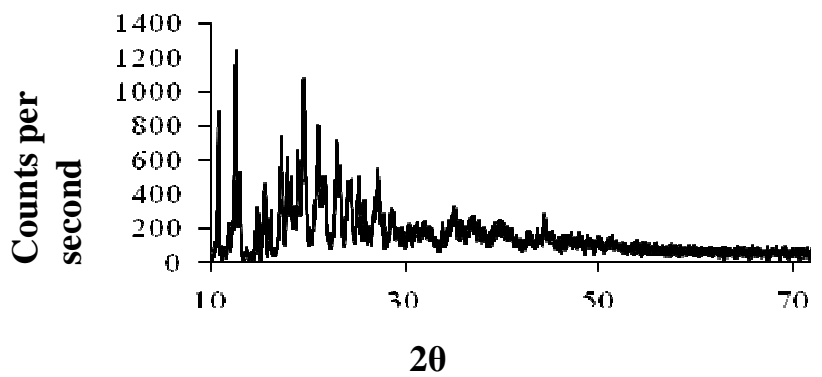

Fig. 13: XRD pattern for kneaded complex of NM and CD (1:5 ratio)

\section{CONCLUSION}

The solubility of the poorly aqueous soluble drug nimesulide was improved by the inclusion complex with $\beta$-cyclodextrin as a carrier. The effect of varying the percentage of water addition in the kneading process was comparatively explained. The formulation prepared with $50 \% \mathrm{w} / \mathrm{v}$ water addition exhibited a significant increase in the solubility and dissolution of the drug release. The flow and physical property of the prepared kneaded granules with improved angle of repose, tab density and Carr's index confirmed the suitability of the mixture to convert into single unit solid dosage forms. The FTIR, TG-DTA and XRD studies confirmed the stability of the kneaded complex formulation without significant chemical alterations of the drug. The carrier compatibility and mild interactions in the formulation were also revealed. The formulated inclusion complex of nimesulide improved the solubility and flow properties to enhance the kinetic behaviour of the drug.

\section{ACKNOWLEDGEMENT}

Authors would like to thank SASTRA University, Thanjavur, India, for giving an opportunity to utilize the laboratory facility and carry out the research work

\section{CONFLICT OF INTERESTS}

The authors declare that there is no conflict of interest

\section{REFERENCES}

1. Chowdary KPR, Enturi V, Kumar PS. Formulation development of nimesulide tablets by wet granulation and direct compression methods employing starch phosphate. Int J Chem Sci 2011;9:1595-606.

2. Shahiwala A, Misra A. Studies in topical application of niosomally entrapped nimusulide. J Pharm Pharm Sci 2002;5:220-5.

3. Tan HH, Ong WM, Lai SH, Chow WC. Nimesulide-induced hepatotoxicity and fatal hepatic failure. Singapore Med J 2007;48:582-5.

4. Chowdary KPR, Enturi V. Factorial studies on the enhancement of dissolution rate of nimesulide tablets employing starch citrate-a new modified starch, PEG 4000 and PVP K-30. Int J Pharm Res Dev 2011;3:224-30.

5. Jin-lei Z, Xue-cai T, Dan-dan Z, Sheng-wei T, Li L, Lin W, et al. $\mathrm{Fe} 304$ magnetic nanoparticles modified electrode as a sensor for determination of nimesulide. Chem Res Chin Universities 2011;27:566-9.

6. Battu PR. Determination of nimesulide in pharmaceutical formulations and in human serum by reverse-phase highperformance liquid chromatography. Int J PharmTech Res 2009;1:206-9.

7. Pushpendra J, Amit M, Yadav SK, Patil UK, Baghel US. Formulation development and characterization of solid lipid 
nanoparticles containing nimesulide. Int J Drug Delivery Technol 2009;1:24-7.

8. Sinha VR, Nanda A, Kumria R. Cyclodextrins as sustainedrelease carriers. Pharm Tech; 2002. p. 36-46.

9. Zaibunnisa AH, Siti Rashima R, Nur Ain AH. Stabilisation of curcumin with $\gamma$-cyclodextrin: phase solubility study and its characterisation. 2nd International Conference on Biotechnology and Food Science, IACSIT Press, Singapore. IPCBEE 2011;7:9-13.

10. Patel HM, Suhagia BN, Shah SA, Rathod IS, Parmar VK. Preparation and characterization of etoricoxib-b-cyclodextrin complexes prepared by the kneading method. Acta Pharm 2007;57:351-9.

11. Miclea LM, Vlaia L, Vlaia V, Hadaruga DI, Mircioiu C. Preparation and characterization of inclusion complexes of meloxicam and $\alpha$-cyclodextrin and $\beta$-cyclodextrin. Farmacia 2010;58:583-93.

12. Ghosh A, Biswas S, Ghosh T. Preparation and evaluation of silymarin $\beta$-cyclodextrin molecular inclusion complexes. J Young Pharm 2011;3:205-10.

13. Sawarikar PP, Sridhar BK, Shivkumar S. Formulation and evaluation of fast dissolving/disintegrating tablets of isoxsuprine hydrochloride. J Curr Pharm Res 2010;3:41-6.

14. Aleti SR, Rangaraju D, Kant A, Shankraiah MM, Venkatesh JS, Nagendra Rao R, Nagesh C. Solubility and dissolution enhancement of cefixime using natural polymer by solid dispersion technique. Int J Res Pharm Chem 2011;1:28-4.

15. Kausalya J, Suresh K, Padmapriya S, Rupenagunta A, Senthilnathan B. Solubility and dissolution enhancement profile of telmisartan using various techniques. Int J PharmTech Res 2011;3:1737-49.

16. Chowdary KP, Nalluri BN. Nimesulide and beta-cyclodextrin inclusion complexes: physicochemical characterization and dissolution rate studies. Drug Dev Ind Pharm 2000;26:1217-20.

17. Srinivas S, Anand Kumar Y, Hemanth A, Anitha M. Preparation and evaluation of niosomes containing aceclofenac. Digest J Nanomaterials Biostructures 2010;5:249-54.

18. Nair AB, Gupta R, Kumria R, Jacob S, Attimarad M. Formulation and evaluation of enteric coated tablets of proton pump inhibitor. J Basic Clin Pharma 2010;1:215-25.

19. Swathi S, Neeharika V, Lakshmi PK. Formulation and evaluation of fast dissolving tablets of freely and poorly soluble drug with natural and synthetic super disintegrants. Drug Invention Today 2011;3:250-6.

20. Diwedi R, Alexandar S, Chandrasekar MJN. Preparation and in vitro evaluation of sustained release tablet formulations of metformin HCl. Asian J Pharm Clin Res 2012;5:45-8.

21. Mankala SK, Korla AC, Gade S. Development and evaluation of aceclofenac-loaded mucoadhesive microcapsules. J Adv Pharm Technol Res 2011;2:245-54.
22. Swami G, Koshy MK, Pandey M, Saraf SA. Preparation and characterization of domperidone-cyclodextrin complexes prepared by kneading method. Int J Adv Pharm Sci 2010;1:68-4.

23. Sudhakar K, Rao KM, Mallikarjuna B, Prasad CV, Subha M, Rao KC. Preparation and characterization of nimesulide loaded poly (methyl methacrylate)/poly (ethylene oxide) blend microspheres: in vitro release studies. Asian J Pharm 2013;7:118-24.

24. Sharma MC, Sharma S. Formulation and spectroscopic studies and dissolution behaviour of levofloxacin-a cyclodextrins inclusion complex. Int J PharmTech Res 2011;3:1883-8.

25. Pyramides G, Robinson JW, Zito SW. The combined use of DSC and TGA for the thermal analysis of atenolol tablets. J Pharm Biomed Anal 1995;13:103-10.

26. Tracy Chen, Oakley DM. Thermal analysis of proteins of pharmaceutical interest. Pharm Thermal Anal 1995;248:229-44.

27. Kim DJ, Cho SK, Choi JH, Koo JM, Seok CS, Kim MY. Evaluation of the degradation of plasma sprayed thermal barrier coatings using nanoindentation. J Nanosci Nanotechnol 2009;9:7271-7.

28. Odeniyi MA, Alfa J, Jaiyeoba KT. Effect of lubricants on flow properties and tablet strength of silicified microcrystalline cellulose. FABAD J Pharm Sci 2008;33:71-5.

29. Dantu AS, Ramyadevi D, Vedhahari BN. Effect of ball milling on the physical dispersions of nimesulide for solubility enhancement. Int J Pharm Sci Rev Res 2013;18:77-4.

30. Mendhe AA, Kharwade RS, Mahajan UN. Dissolution enhancement of poorly water soluble drug by cyclodextrins inclusion complexation. Int J Appl Pharm 2016;8:60-5.

31. Jha AK, Bhattacharya A, Verma P. Formulation and in vitro evaluation of sustained release matrix tablets of metoprolol succinate using hydrophilic polymers. Int J PharmTech Res 2009;1:972-7.

32. Khan SA, Ahmad M, Murtaza G, Aamir MN, Rehman NU, Kousar $\mathrm{R}$, et al. Formulation of nimesulide floating microparticles using low-viscosity hydroxypropyl methylcellulose. Trop J Pharm Res 2010;9:293-9.

33. Vavia PR, Adhage NA. Inclusion complexation of nimesulide with beta-cyclodextrins. Drug Dev Ind Pharm 1999;25:543-5.

34. Manna S, Jayasri K, Annapurna KR, Kanthal LK. Alginate based gastro-retentive raft forming tablets for enhanced bioavailability of tinidazole. Int J Appl Pharm 2017;9:16-21.

\section{How to cite this article}

- $\quad$ Shankarguru P, Ramya Devi D, Vedha Hari BN. Effect of water content in kneading method of solid dispersion technique for solubility enhancement. Int J Appl Pharm 2017;9(5):14-21. 